\title{
A Simple Key for Identifying the Sibling Species of the Malaria Vector Anopheles gambiae (Giles) Complex by Polytene Chromosome Cytogenetics
}

\author{
Music T. OBEMBE*, Idowu J. AWOPETU, Michael O. AWODIRAN \\ Obafemi Awolowo University, Faculty of Science, Department of Zoology, P.M.B. 13 OAU, Ile-Ife, \\ Nigeria;mzktop@gmail.com (*correspondingauthor);idouawopetu@yahoo.com;michfemi@yahoo.com
}

\begin{abstract}
It has been established that Anopheles gambiae complex sibling species are the major Plasmodium malaria vectors in Africa; however, not all the sibling species transmit the infection. Easier molecular methods, PCR-based assays, have been developed to distinguish the several members of the A. gambiae complex. However, malaria vector research in less developed countries, particularly sub-Saharan Africa, is being hampered by the lack of PCR facilities in laboratories and the cost of carrying out the assay within lack of funding. Hence, the present study was designed to develop a simple identification key, based on an affordable method of polytene chromosome cytotaxonomy, for identifying the major $P$. falciparum vectors. The Identification Key was successfully used to identify two members of the $A$. gambiae complex, $A$. gambiae sensu stricto and $A$. arabiensis, which are the most potent malaria vectors in Africa; even so, it could not be used to establish the infective and the refractory strains.
\end{abstract}

Keywords: Anopheles arabiensis, A. gambiae, cytotaxonomy, photomap, polytene chromosome, sensu stricto

\section{Introduction}

Malaria remains a major burden to human health in the sub-tropical and tropical regions of the world, where Plamodium malaria is the most prevalent and infectious (WHO, 1993; Hoffman et al., 1996; Davidson, 2000; WHO, 2009). Plasmodium consists of four species, $P$. falciparum, P. vivax, P. malariae and $P$. ovale that cause human malaria (Nonstrand, 1978). Among the four species, $P$. falciparum is the most deadly (Hoffman et al., 1996; Miller and Marley, 1999). Sub-Saharan Africa, however, suffers from the highest global malaria transmission levels, and hence, high mortality rate due to malaria (Fontenille and Simard, 2004; Hay et al., 2005 and 2009); in Nigeria alone, ninety percent of malaria infections are caused by $P$. falciparum. $P$. falciparum is adapted to propagating alternately in Anopheles mosquitoes and human beings (Wikipedia, 2013).

The $A$. gambiae complex members are the dominant vectors of malaria in sub-Saharan Africa (Sinka et al., 2010; Gregory and Yoosook, 2013). A. gambiae complex consists of eight sibling species, which include $A$. gambiae sensu stricto Giles; $A$. bwambae White; $A$. merus Dönitz; $A$. arabiensis Patton; $A$. quadriannulatus Theobald; $A$. ambaricus Hunt, Coetzee and Fettene; $A$. melas Theobald; A. comorensis Brunhes, le Goff and Geoffroy (Gillies and DeMeillon, 1968; White, 1974 and 1985; Hunt et al., 1998; Harbach, 2003; Coetzee et al., 2013). Amongst these sibling species, A. gambiae and A. Arabiensis are the two major malaria vectors in Africa (Gillies and De Meillon 1968), particularly in Nigeria (Boreham et al., 1979; Onyabe and Conn, 2001; Obembe and Awopetu, 2014). There are strains of $A$. gambiae complex sibling species in which the parasite cannot complete its life cycle; such strains are said to be refractory (Collins et al., 1986; Chris et al., 2011; Obembe and Awopetu, 2014).

Members of $A$. gambiae complex are morphologically identical, but genetically distinctive (Coluzzi et al., 1979). Due to the genetic distinction, the sibling species can be distinguished by their polytene chromosome cytotaxonomy and molecular methods. The polytene chromosome cytotaxonomy is based on chromosomal inversions of the ovarian nurse cell polytene chromosomes (Coluzzi $e t$ al., 1979; George et al., 2010). Ten fixed inversions that can be used to differentiate the members of $A$. gambiae complex have been identified (Coluzzi et al., 1979; Coluzzi et al., 2002). In addition, drawings that depict the banding 
patterns of $A$. gambiae s.l. polytene chromosomes are now available for characterizing the divisions and subdivisions of the species, as well as the locations of the inversions (Coluzzi et al., 2002; Holt et al., 2002). The molecular method is PCR-based and refers to species-specific single nucleotide polymorphisms (SNPs) in the intergenic spacer region (IGS) of the $A$. gambiae DNA (Scott et al., 1993; Fettene and Temu, 2003; Besansky et al., 2006; Wilkins et al., 2006).

The polytene chromosome cyto-taxonomic method is affordable, but it can only differentiate semi-gravid females, which constitute a small proportion of mosquito population in the wild; molecular method is easier and it can identify all stages and genders in the population. Nevertheless, in sub-Saharan Africa, particularly in Nigeria, the use of molecular method in identifying the members of malaria vector species complexes is restricted by lack of the PCR facilities in laboratories and the cost of carrying out the assay coupled with lack of research funding; consequently, malaria vector research is restricted. Hence, there is need for a simple identification key based on the affordable polytene chromosome cytotaxonomy so as to encourage malaria vector research in Africa.

\section{Materials and Methods}

\section{Studyarea}

Two selected areas in Osun State, Ilesa $\left(4^{\circ} 44^{\prime} \mathrm{E}, 7^{\circ} 37^{\prime} \mathrm{N}\right)$ and Ile-Ife $\left(7^{\circ} 28^{\prime} \mathrm{N}, 4^{\circ} 34^{\prime} \mathrm{E}\right)$, in South-Western Nigeria were sampled. Anopheles larvae were collected from stagnant pools of water in these locations and transported to the laboratory at Obafemi Awolowo University, Ile-Ife, Nigeria. The Anopheles larvae were identified by using their resting position in water, as well as a diagnostic feature, lack of a respiratory siphon but spiracles on the 8th abdominal segment.

\section{Rearing F1 generations of Anopheles mosquitoes}

The Anopheles larvae collected from the study areas were used to breed $\mathrm{F}_{1}$ colonies of Anopheles larvae in the laboratory. The $\mathrm{F}_{1}$ Anopheles larvae species were validated by observing the diagnostic features, resting position of the larvae in water, absence of breathing siphon and presence of palmate hairs on the eighth and fourth abdominal segments respectively, under a dissecting microscope (WHO, 1997; Mark et al., 2007). The validated $\mathrm{F}_{1}$ Anopheles larvae were fed with biscuit diet until they emerged as adults. Gender grouping of the $F_{1}$ adult mosquitoes was carried out on the third day of emergence based on their diagnostic features, antennae and palps structures (Service, 1980; WHO, 1997).

\section{Separation offemale Anopheles gambiae from the stock}

The $\mathrm{F}_{1}$ female Anopheles mosquitoes were anaesthetized on the fourth day and $A$. gambiae females were selected from the stock using a standard identification key (Mark et al., 2007). Further species authentications were carried out by using the collated Identification Key from Hamon and Adam (1963), De Meillon (1947) and Evans (1938). The female $A$. gambiae mosquitoes that were identified were infected with $P$. falciparum.

\section{Female A. gambiae infection}

In preparation for the infection experiment, the $F_{1}$ female mosquitoes were starved for 18 to 20 hours. On the day-5, after emergence, the female mosquitoes were allowed to feed on a pre-diagnosed $P$. falciparum infected individual for about 15 minutes such that the mosquitoes became engorged. Mosquitoes that did not feed on the infected individual, as well as the ones that were not engorged, were sacrificed in chloroform. The infected mosquito colonies were kept on $10 \%$ sugar solution regimen in the laboratory with ambient temperature, between $26^{\circ} \mathrm{C}$ and $32^{\circ} \mathrm{C}$. They were maintained in the laboratory for 16 to 18 days after infection, such that $P$. falciparum would have reached their salivary glands (WHO, 1975).

\section{Identification of the A. gambiae sibling species}

Sibling species identification was carried out by using a simple Identification Key developed from Coluzzi et al. (2002) and George et al. (2010) (Table 1). The infected mosquitoes were deprived of food for 18 to 20 hours after which they were fed with blood a day before the dissection. Half gravid females (Clements, 1992) were dissected between 20 - 24 hours after blood feeding for ovarian extraction. Stained polytene chromosome spreads were prepared from fixed ovaries (Cornel, 2007). Images of the polytene chromosome spreads that showed suitable levels of polytenization were obtained by using the digital imaging system of the Accuscope 3000 LED phase contrast microscope (Accuscope Inc., 2011). The chromosome images were processed by the Macormedia Fireworks image editing software version 8.0 (Macromedia Inc., 2005). Chromosome arm recognition was carried out by using standard arm recognition landmarks (George et al., 2010). With reference to Coluzzi et al. (2002) and George et al. (2010), 2R arm cytogenetic maps of the mosquito polytene chromosomes were developed and the inversion $(2 \mathrm{Rj}, 2 \mathrm{R} b$, $2 \mathrm{R} c, 2 \mathrm{R} u$ and $2 \mathrm{R} d$ ) breakpoints were characterized. The Identification Key in Table 1 was successfully used for identifying the sibling species of the mosquitoes.

Table 1. Simple identification key for identifying the sibling species of $A$. gambiae complex using common polymorphic inversions

\begin{tabular}{|c|c|c|c|c|c|c|}
\hline Inversion & A. gambiae & A. arabiensis & A. bwambae & A. melas & A. merus & A. quadriannulatus \\
\hline $2 \mathrm{Rj}$ & + & - & - & - & - & - \\
\hline $2 \mathrm{R} b$ & + & + & - & - & - & - \\
\hline $2 \mathrm{R} c$ & + & + & - & - & - & - \\
\hline $2 \mathrm{R} u$ & + & - & - & - & - & - \\
\hline $2 \mathrm{R} d$ & + & - & - & - & - & - \\
\hline
\end{tabular}


The infective and the refractory strains

The mosquito salivary glands were dissected immediately after ovary extraction. A drop of physiological solution (Hayes, 1953) and a cover slip were then placed on the salivary glands. They were broken by a gentle pressure applied to them in order to free the sporozoites into the physiological solution. The glands were then inspected under $\mathrm{x} 40$ objective of microscope for infection by $P$. falciparum.

\section{Results}

$P$. falciparum sporozoites were observed in the salivary glands of the mosquitoes, which indicated that the mosquitoes were susceptible to $P$. falciparum infection, and hence, they were infective. However, the salivary glands of some of the mosquitoes did not bear sporozoites, indicating that those mosquitoes were refractory to $P$. falciparum infection. Infective and the refractory strains were recorded in both locations.

\section{Proportions of the infective and the refractory strains}

Table 2 shows the proportions of the infective and the refractory strains of the $A$. gambiae mosquitoes from the two study areas. There was a significant difference between the proportions of infective and refractory strains within each study area $(P<0.05)$; contrarily, the proportions of refractory strains with the proportions of infective strains were not significantly different between the two study areas $(P>0.05)$.

\section{Sporozoite rate}

Sporozoite rates of the mosquitoes from both study areas are shown in Table 3. The sporozoite rates between the study areas were not significantly different $(P>0.05)$.

\section{Siblingspecies identification}

The Identification Key (Table 1) was successfully used to identify two sibling species, $A$. gambiae sensu stricto and $A$. arabiensis, of the $A$. gambiae complex. The observed infective strains include the two members of the complex, $A$. gambiae sensu stricto and $A$. arabiensis. It was noted that $A$. gambiae sensu stricto was the only refractory strain recorded. The infective strain and the refractory strain of $A$. gambiae sensu stricto have the same banding patterns, and hence, they could not be distinguished by the Identification Key.

\section{Discussion}

There is insufficient information on the identification of the sibling species of malaria vectors and their infective and refractory strains in south-western Nigeria (Obembe and Awopetu, 2014), perhaps, due to lack of facilities and funding for carrying out the molecular, PCR-based assay, method of identification. Hence, the current study was designed to promote malaria vector research, not only in Nigeria, but also in other less developed countries of the world, particularly in sub-Saharan Africa.

The proportions of $A$. gambiae complex recorded in the study areas were high, which shows that the members of $A$. gambiae complex are greatly susceptible to $P$. falciparum infection. In a similar research by Obembe and Awopetu (2014) in the study area, virtually, the same results were obtained. Similar reports were also recorded by Collins et al. (1986) and Alvaro et al. (2012). This corroborates the idea that the parasites are capable of evading the mosquito immune responses (Osta et al., 2004). However, the fact the parasite was not successful in reaching the salivary glands of some of the mosquito's supports the reports by Julián (2010) and Chris et al. (2011) that the mosquito inherent defence system is capable of terminating the development of all the parasites before they reach the salivary glands leading to total refractoriness. It also confirms the report by Obembe and Awopetu (2014) that refractory strains of $A$. gambiae are present in South-Western Nigeria, though at a very low frequency.

However, the sporozoite infection rates that were obtained were significantly higher than the ones previously reported, $6.70 \%$ and $6.30 \%$ in 2001 and 2002 respectively, at Igbo-Ora, Oyo State in South-Western Nigeria (Noutcha and Anumdu, 2009), as well as at Badagry Axis of Lagos Lagoon, Lagos State, Nigeria (Oyewole et al., 2010).

Table 2. Proportions of refractory (R) and infective (I) A. gambiae mosquitoes from the study areas

\begin{tabular}{cccccc}
\hline \multirow{2}{*}{ Study Area } & $\mathrm{a}$ & $\mathrm{b}$ & $\mathrm{c}$ & $\mathrm{d}$ & $\mathrm{e}$ \\
\cline { 2 - 6 } & $\begin{array}{c}\text { Total number of } \\
\text { mosquitoes dissected }\end{array}$ & Number of $\mathrm{R}$ & Number of $\mathrm{P}$ & $\begin{array}{c}\text { Proportion of R } \\
(\mathrm{b} / \mathrm{a})\end{array}$ & $\begin{array}{c}\text { Proportion of } \\
\mathrm{I}(\mathrm{c} / \mathrm{a})\end{array}$ \\
\hline Ilesa & 58 & 12 & 46 & 0.207 & 0.793 \\
Ile-Ife & 62 & 11 & 51 & 0.178 & 0.823 \\
Overall & 120 & 23 & 97 & 0.192 & 0.808 \\
\hline R & & & &
\end{tabular}

$\mathrm{R}=$ Refractory mosquitoes; I = Infective mosquitoes

Table 3. Sporozoite infection rates of $A$. gambiae mosquitoes from the study areas

\begin{tabular}{cccc}
\hline \multirow{2}{*}{ Study Area } & $\mathrm{a}$ & $\mathrm{b}$ & $\mathrm{c}$ \\
\cline { 2 - 4 } & $\begin{array}{c}\text { Total number of mosquitoes } \\
\text { dissected }\end{array}$ & Number of infective mosquitoes & Sporozoite infection rate (\%) (b/ax 100) \\
\hline Ilesa & 58 & 46 & 79.31 \\
Ile-Ife & 62 & 51 & 82.23 \\
Overall & 120 & 97 & 80.83 \\
\hline
\end{tabular}


100

However, Obembe and Awopetu (2014) has reported similarly high $P$. falciparum sporozoite rates in the study areas. Okwa et al. (2006) also reported a high sporozoite rate (62.9\%) for A. gambiae in Badagry area of Lagos, Nigeria. In a related study, $83.52 \% P$. falciparum sporozoite infection rate was recorded for $A$. gambiae (Ndiath $e t$ al., 2011). The high $P$. falciparum sporozoite rates shows that the $A$. gambiae complex members are prominent and potent $P$. falciparum vectors in South-Western Nigeria and similar report was given by Gilles and Coetzee (1987), Annon (2003), Okwa et al. (2007) and Okwa et al. (2008).

The identified members of the $A$. gambiae complex, $A$. gambiae sensu stricto and $A$. arabiensis, as similarly reported by Okwa et al. (2008) and Obembe and Awopetu (2014), are the major $P$. falciparum vectors in South-Western Nigeria.

\section{Conclusions}

The present study showed that $A$. gambiae sensu stricto and $A$. arabiensis are potent malaria vectors in southwestern, Nigeria. In addition, they can be identified by the Identification Key based on the affordable ovarian polytene chromosome cytotaxonomy. However, the method could not be used to characterize the refractory and infective strains of the A. gambiae sensu stricto.

\section{References}

Accuscope Inc. (2011). Accusope microscope user's guide. www.accuscope.com.

Alvaro M, Randall JD, Corrie O, Ashley H, Ekua A, Janneth R, Giovanna J, Carolina B (2012). Some strains of Plasmodium faliparum, a human malaria parasite, evade the complement-like system of Anopheles gambiae mosquitoes. Forest Ecology and Management 267:297-308.

Annon (2003). Africa malaria reports. Executive summary. Retrieved on 2014January 10 from hettp://www.who.int.

Benedict MQ (2014). Methods in Anopheles Research (4th ed). CDC, Atlanta USA.

Besansky NJ, Collins FH, Townson H (2006). A species-specific PCR for the identification of the malaria vector Anopheles bwvambae. Annals of Tropical Medicine and Parasitology 100:277-280.

Boreha PE, Lenahan JK Boulzaquet R, Storey J, Ashkar TS, Nambiar R, Matsushima T (1979). Studies on multiple feeding by Anopheles gambiae s. 1 in a Sudan savannah area of northern Nigeria. Transactions of the Royal Society of Tropical Medicine and Hygiene 73: 418-423.

Chris MC, April MC, George D (2011). Low- and high-tech approaches to control Plasmodium parasite transmission by Anopheles Mosquitoes. Journal of Tropical Medicine 891342:6.

Clements AN (1992). The biology of mosquitoes: Development, nutrition and reproduction. Chapman \& Hall, London.

Coetzee M, Hunt RH, Wilkerson R, della Torre A, Coulibaly MB, Besansky N (2013). Anopheles coluzzii and Anopheles ambaricus, new members of the Anopheles gambiae complex.Zootaxa 3619(2):246-274.

Collins FH, Sakaim RK, Vernick KD, Paskewitz S, Seeley DC, Miller LH,
Collins WE, Campbell CC, Gwadz RW (1986). Genetic selection of a Plasmodium-refractory strain of the malaria vector Anopheles gambiae. Science 234:607-610.

Coluzzi M, Sabatini A, Petrarca V, Di Deco MA (1979). Chromosomal differentiation and adaptation to human environments in the Anopheles gambiae complex. Transactions of the Royal Society of Tropical Medicine and Hygiene 73(5):483-497.

Coluzzi M, Sabatini A, Della Torre A, Di Deco MA, Petrarca V (2002). A polytene chromosome analysis of the Anopheles gambiae species complex. Science 298:1415-1418.

Cornel A (2007).Methods in Anopheles research. Pp 277.

Davidson L (2000).Malaria. The Horn NewspaperNigeria, LT Publication pp 11-14.

De Meillon B (1947). The Anophelini of the Ethiopian geographical region. Publication of South African Institute for Medical Research 10(49):1272.

Evans AM (1938). Mosquitoes of the Ethiopian region II. (British Museum (Natural History).Entomology 9(1):59-65.

Fettene M, Temu EA (2003). Species-specific primer for identification of Anopheles quadriannulatus sp. B (Diptera: Culicidae) from Ethiopia using a multiplex polymerase chain reaction assay. Journal of Medical Entomology 40:112-115.

Fontenille D, Simard F (2004). Unravelling complexities in human malaria transmission dynamicsin Africa through a comprehensive knowledge of vector populations. Comparative Immunology, Microbiology and Infectious Diseases 27(5):357-375.

George P, Sharakhova MV, Sharakhov IV (2010). High-resolution cytogenetic map for the African malaria vector Anopheles gambiae. Insect Molecular Biology 19(5):675-682.

Gilles MT, Coetzee MA (1987). A supplement to the anophelinae of Africa south of the Sahara (Afro Tropical Region). In: Publications of the South African Institute for Medical research. Johannesburg, pp 55.

Gillies M, deMeillon B (1968). The anophelinae of Africa south of Sahara (Ethiopian zoogeographical region).The Anophelinae of Africa south of the Sahara (Ethiopian Zoogeographical Region).

Gregory CL, Yoosook L (2013). Speciation in Anopheles gambiae - The distribution of genetic polymorphism and patterns of reproductive isolation among natural populations. and patterns of reproductive isolation among natural populations. In: Anopheles mosquitoes-New insights into malaria vectors. InTech. Retrieved on 2015 June 05 from http://dx.doi.org/10.5772/56232.

Hamon J, Adam JP (1963). In Russell, West, Manwell and Macdonald: Practical malariology. Oxford University Press, 2nded, appendix 3:660.

Harbach R (2003). Mosquito taxonomic inventory. Retrieved on 2014 November 12 from http://mosquito-taxonomic-inventory.info/. Available from: http://mosquito-taxonomic-inventory.info/sites /mosquito-taxonomic-inventoryinfofiles/Anopheles\%20classifi cation_25.pdf

Hay SI, Guerra CA, Gething PW, Patil AP, Tatem AJ, Noor AM, Kabaria CW, Manh BH, Elyazar IR, Brooker S, Smith DL, Moyeed RA, Snow RW (2009). A world malaria map: Plasmodium falciparum endemicity in 2007.PLoSMedicine. 6(3):e1000048.

Hay SI, Guerra CA, Tatem AJ, Atkinson PM, Snow RW (2005). 
Urbanization, malaria transmission and disease burden in Africa. Nature Reviews Microbiology 3(1):81-90.

Hayes RO (1953). Determination of a physiological saline solution for Aedes aegypti (L.).Journal of Economic Entomology 46:624-627.

Hoffman SL, FrankeED, Hollingdale MR, Druilhe P (1996). Attacking the infected hepatocyte. In Malaria vaccine development: A multi-immune response approach (ed. S. L. Hoffman), Washington, DC: ASM Press pp 35-75.

Holt RA, Subramanian GM, Halpern A, Sutton GG, Charlab R, Nuskern DR, Wincker $P$ et al. (2002). The genome sequence of the malaria mosquito Anopheles gambiae. Science 298:129-149.

Hunt RH, Coetzee M, Fettene M (1998). The Anopheles gambiae complex: a new species from Ethiopia. Transactions of the Royal Society of Tropical Medicine and Hygiene 92(2):231-235.

Julián FH (2010). Mosquito immunity. Invertebrate immunity, edited by Kenneth Söderhäll. Landes Bioscience and Springer Science + Business Media 12:218-232.

Macromedia Inc. (2005).www.Macromedia.org.

Miller SA, Marley JP (1999). Zoology, 4th ed. WMC Brown Publishers, Debuque Lowa Melbourne, Australia pp 251-253.

Ndiath MO, Cohuet A, Gaye A, Konate L, Mazenot C, Faye O, Boudin C, Sokhna C, Trape J (2011). Comparative susceptibility to Plasmodium falciparum of the molecular forms $\mathrm{M}$ and $\mathrm{S}$ of Anopheles gambiae and Anopheles arabiensis. Malaria Journal 10:269.

Nonstrand V (1978). Malaria in scientific encyclopedia. 6th Edition Van Nonstrand Reinhold Company pp 1812-1813.

Noutcha MAE, Anumdua CI (2009). Entomological indices of Anopheles gambiae sensu lato at a rural community in south-west Nigeria. Journal of Vector Borne Diseases 46:43-51.

Obembe MT, Awopetu JI (2014). Sporozoite rate and identification of the infective and refractory species of Anopheles gambiae (Giles) complex in southwestern Nigeria. Notulae Scientia Biologicae 6(4):407-413.

Okwa OO, Akinmolayan FI, Carter V, Hurd H (2008). Transmission dynamics of malaria in four selected ecological zones of Nigeria in the rainy season. Annals of African Medicine 8(1):1-9.

Okwa OO, Carter V, Hurd H (2006). Abundances, host preferences and infectivity rates of malaria vectors in Badagry Local Government Area of Lagos, Nigeria. Nigerian Journal of Parasitology 27:41-48.

Okwa OO, Rasheed A, Adeyemi A, Omoyeni M, Oni L, Fayemi A, Ogunwomoju A (2007). Anopheles species abundances, composition and vectoral competence in six areas of Lagos: Nigeria. Journal of Cell and Animal Biology 1(2):019-023.

Onyabe DY, Conn JE (2001). Population genetic structure of the malaria mosquito Anopheles arabiensis across Nigeria suggests range expansion. MolecularEcology 10:2577-2591.
Osta MA, Christophides GK, Kafatos FC (2004). Effects of mosquito genes on Plasmodium development. Science 303:20300-2032.

Oyewole IO, Ibidapo CA, Okwa OO, Oduola AO, Adeoye GO, Okoh HI, Awolola TS (2010). Species composition and role of Anopheles Mosquitoes in malaria transmission along Badagry Axis of Lagos Lagoon, Lagos, Nigeria. International Journal of Insect Science 2:51-57.

Scott JA, Brogdon WG, Collins FH (1993). Identification of single specimens of the Anopheles gambiae complex by the polymerase chain reaction. The American Journal of Tropical Medicine and Hygiene 49:520-529.

Service MW (1980). A guide to medical entomology. Macmillan Press Limited,London.

Sinka ME, Bangs MJ, Manguin S, Coetzee M, Mbogo CM, Hemingway J, Patil AP, Temperley WH, Gething PW, Kabaria CW, Okara RM, Boeckel TV, Godfray HCJ, Harbach RE, Hay SI (2010). The dominant Anopheles vectors of human malaria in Africa, Europe and the Middle East: occurrence data, distribution maps and bionomic précis. Parasites and Vectors 3:117.

White GB (1985). Anopheles bwambae sp.n, a malaria vector in the Semliki Valley, Uganda, and its relationships with other sibling species of the $A$. gambiae complex (Diptera, Culicidae). Systematic Entomology 10(4):501-522.

White GB (1974). Anopheles gambiae complex and disease transmission in Africa. Transactions of the Royal Society of Tropical Medicine and Hygiene 68:278-298.

WHO (1975). Manual on practical entomology in malaria. Part II. In. World Health Organization, Geneva.

Wikipedia, the free encyclopedia (2013). Malaria, manual and Guide Book. Retrieved on 2014 January 15 from http://en. wikipedia.org/wiki/Malaria.

Wilkins EE, Howell PI, Benedict MQ (2006). IMP PCR primers detect single nucleotide polymorphisms for Anopheles gambiae species identification, Mopti and Savanna rDNA types, and resistance to dieldrin in Anopheles arabiensis. Malaria Journal 5:125.

World Health Organization, WHO (1993). A Global Strategy for Malaria Control. WHO, Geneva. Retrieved on 2014 March 13 http://whqlibdoc. who.int/ publications/9241561610.pdf.

World Health Organization, WHO (1997). Mosquitoes and other biting Diptera, Chapter 1. Retrieved on 2014 October 15 from http://www.who.int/water_sanitation_health/resources/vector007to2 8.pdf.

World Health Organization, WHO (2009). World Malaria Report, 1p. Retrieved on 2015 May 10 from http://whqlibdoc.who.int/ publications/2009/9789241563901_eng.pdf 